\title{
Field Survey
}

National Cancer Institute

\section{Source}

National Cancer Institute. Field Survey. NCI Thesaurus. Code C39404.

A descriptive or analytic study of risk factors or disease determinants in populations.

Most epidemiologic and some genetic studies fit within this category. 